\title{
A Clinical Quiz: What Is Your Diagnosis?
}

\author{
Hamdi Hassan Shelleh ${ }^{1 *}$, Hamad A. Al-Fahaad ${ }^{2}$ \\ ${ }^{1}$ Dermatology Department, Najran General Hospital, Najran, Saudi Arabria; ${ }^{2}$ Medical College, Najran University, Najran, Saudi Arabria. \\ Email: ${ }^{*}$ hhs_s2000@hotmail .com
}

Received October $13^{\text {th }}, 2011$; revised October $25^{\text {th }} ; 2011$; revised November $9^{\text {th }}, 2011$

\begin{abstract}
We present a case of conventional/classic type of Erythema abigne (Eai) as a quiz. The diagnosis is straightforward with satisfying the diagnostic "H triad": 1) history of cold weather, 2) heat source exposures-prolonged and or frequent, and 3) hyper-pigmentation-reticulate dusky erythematous and confined to the exposed sites-, then the diagnosis is outstanding, and a $4^{\text {th }} \mathrm{H}$; confirmatory his topathological assay may be avoided. Otherwise, in case of confusion by missing any $\mathrm{h}$ of the $\mathrm{h}$ triad the $4^{\text {th }} \mathrm{H}$ should be seeked. Eai is frequently found in literature as a clinical quiz, but it is in fact not prevalent, though in started recently to report a spike with the advent of global weather changes and modern laptop technology. The different categories of Eai-s depending on the different causes are elaborated here in the paper, and the different complications as well. This quiz case in published as a reminder of Eai, in order to raise the attention of clinicians to this rare transforming dermatosis, as Eai might herald a cancer, or it may potentially evolve to a cancer, hence; it fluctuates between two cancers, thus it worth alarming.
\end{abstract}

Keywords: Erythema Abigne; Diagnostic Criteria of Erythema Abigne; H Triad of Erythema Abigne; Clinical Quiz; KSA

\section{Case Report}

An 18 years old dark skinned Saudi girl attended skin outpatient department for asymptomatic blackish discoloration on the legs since three months, with a small burn on right leg since seven days. The burn was induced by electric heater. There was slight transient itching at onset which disappeared later. The discolored lesion was initially reddish, evolved to dark red, and lastly to deep hyperpigmentation. She was otherwise healthy, not on any drugs for any disease before. On clinical examination, she was a lane healthy girl, vital signs were within normal limits, systemic examination was not remarkable. Skin examination showed macular mesh-like hyperpigmented streaks easily distinguishable though she was black skinned. There were slight telangectatiec changes located on the margin of the pigmented streaks which mottled with normal skin in a reticulate pattern. The lesions were symmetrically distributed on the anterior aspects of the lower and middle parts of legs (Figure 1). A small superficial linear burn existed on the right leg (Figure 2). Routine laboratory and hormonal assay was within normal limits, thus ruling out any underlying potential thyroid disease or other internal diseases.

\section{Questions}

What is your diagnosis?

"Corresponding author.

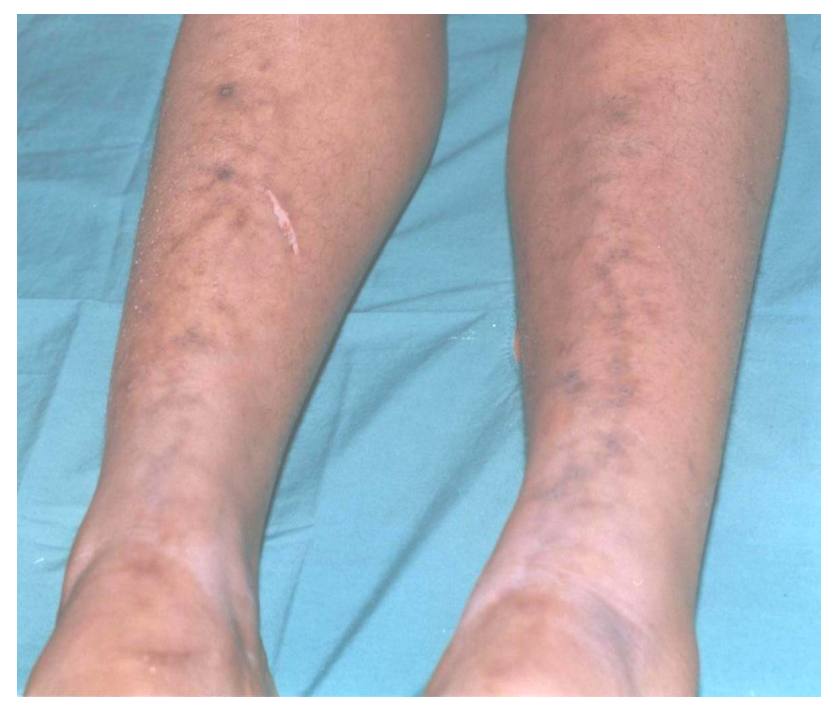

Figure 1. Hyper-pigmented reticulate streaks on anterior of legs.

What does the terminology mean?

What are the differential diagnoses?

What are the possible complications?

What is the clinical significance of this lesion?

\section{Discussion}

This is a classic case of erythema ab igne (Eai), a skin 


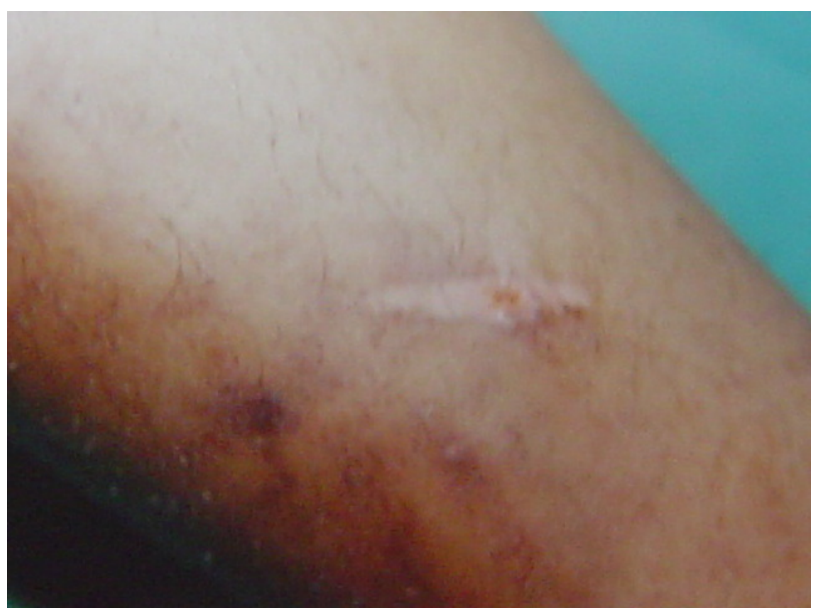

Figure 2. Close up view shows a linear scar.

reaction caused by frequent exposure to infrared radiation in heat form. It was once a common pigmentary dermatosis in the USA and other western countries, particularly in the elderly ladies who used to sit close to open fires or electric heaters to counteract cold. Although the introduction of central heating has reduced it, yet, it is still found in individuals who are obligatorily exposed to heat from other sources in the context of vocational practice or thermotherapy. Eai is not usually encountered in a hot semitropical country like KSA, but started to intrude on clinical field with the late cold weather episodes which attacked the region in the last few years during that we met this case. Eai as a term is derived from Latin and means "redness from fire", it was first described by Perry [1] in 1900 as a reticulate melanoderma which develops on areas frequently exposed to thermal energy with an intensity insufficient to burn the skin but to roast it; hence the descriptive synonymous "roasted skin syndrome". The incidence in the United States has been declining with the advent of central heating but recently increased again. Our patient admitted being frequently exposed to a close electric heater within the past three months, in order to accommodate the sharp cold weather. Thus, the case belongs to the conventional/classic type of Eai in which the diagnosis is straightforward with satisfying the triad of $\mathrm{H}: 1$ ) history of "h/o" cold weather; 2) heat source exposures-prolonged and frequent; and 3) hyperpigmentation reticulate dusky erythematous and confined to the exposed sites, then the diagnosis is due, and further histopathological assay becomes a luxury procedure [2]. The occasional burns which she used to get reflect how close to the heater she used to be. Eia is a thermal assault; it starts on limited exposure to heat as a mild and transient reddish rash of lattice shape which tends to fade out rapidly. It traces the underlying vascular template of the skin, thus has a similar lattice appearance. After two to three weeks of repeated exposures the accumulative thermal insult results in stable erythema; or the erythematous stage in which the prolonged and repeated exposures allow incomplete fading to sustain between successive erythemas. By time, overlap and replacement of the dusky erythema by pigmentation occur gradually until diffuse constant melanosis finally occurs on the insulted area; that is the pigmented stage. Later, the clinical picture is completed by adding atrophic changes on the long run. The skin and underlying tissue here start to thin and sores may rarely develop, thus results in similar clinical and pathological features of poikiloderma, hence called poikilodermic stage or poikiloderma artifacta. Aging was assumed to be a predisposing factor, that may be true in the classical [3], but not in the other types of Eai-s which include Eai-s of vocational etiology. Occupations like silversmiths and jewellers with exposed faces, bakers and chefs with exposed arms are likely to get Eai on the corresponding regions. Repeated exposure to heating sources from car heaters or furniture with built-in heaters is a potential cause of Eai as well $[4,5]$. A new Eai termed "computer induced Eai" was reported and may be added to this vocational type; it is due to the heat originated from the optical drive, fan or battery of the computer. Around a dozen of cases were reported until now. The localization on the thighs and asymmetry are assumed to be characteristic [2,6-9]. Eai occurs on the frequently exposed sites to topical hydro-and thermotherapies like repeated hot water baths or frequent application of hot water containers to treat chronic pain, e.g. chronic backache, or chronic arthritis [10] lumbago, Crohn's disease [11], chronic pancreatitis etc... [12,13], and internal malignancies [14], and pulmonary tuberculosis [15]. Iatrogenic causes like cooling blanket used in the intensive care unit and implant-based breast reconstruction may cause Eai $[16,17]$. It is vital to notice that Eai may be the first presentation in some diseases, and may act as a useful diagnostic sign $[14,18-20]$. It also may be the diagnostic clue for systemic diseases like hypothyroidism, diabetic neuropathy [21] and a variety of psychosocial disorders in socially compromised groups, and in alcoholics like thermophilia, hypothermia and eating disordersanorexia nervosa and bulimia nervosa- $[22,23]$ in which Eai may be a diagnostic marker as well. All these Eai-s differ from the classic one in having different locations and shapes tracing the site and size of the device used. In the differential diagnosis, in addition to poikilo- derma, levido-reticularis has lattice appearance and occurs on the legs; as in classic Eai, but it is more symmetrical, more telangiectatic and less pigmented [24]. Cutis marmorata is a common transient physiological reaction to cold with network pattern as well, but it lacks telangiectasia and disappears rapidly on re-warming. The Japanese colleagues might rule out prurigo pigmentosa there which is confined to their peo- 
ple, though it is rarely reported in other countries [25]. In histologic sections, poikiloderma again should be excluded because of the big patho-similarities with Eai as mentioned [26]. However, it is vital to remind that the diagnostic " $3 \mathrm{H}$ rule" is valid here in Eai-s of etiology other than classical Eai; "professional or physiotherapeutic", and "h/o" seeks for a hot job or chronic painful disease in these cases. This refers us again to the mainstay role of good history taking in building the diagnosis. The complications are rare and may emerge on longstanding exposure to heat for a long period. These include thermal keratosis, Bowen's disease, squamous cell carcinoma and Markel cell carcinoma [27-34]. It is worth mention that the Eai area may become a preferable site of psoriasis and lichen planus to localize on as a Koebner phenomenon [22]. Management of Eai is by: 1) Prevention: avoiding direct exposure to close heaters, providing proper clothing and using indirect "central" heating whenever possible; 2) excluding any underlying diseases aforementioned like "hypothyroidism, hypothermia, chronic pancreatitis, chronic alcoholism, internal malignancy etc..."; 3) excluding any underlying social deprivation "lonely poor old woman", and providing them the necessary social aid; and 4) by elimination of carcinoma in situ and thermal keratosis, which may finally complicate the lesion, as early as possible [28] by different modalities like surgical excision and grafting, 5-fluouracil cream, cryocautery etc. Erythema ab igne was recently successfully treated using 1064-nm Q-switched neodymium-doped yttrium aluminum garnet laser with low fluence by some authors [35].

Finally, we present this quiz as a reminder in order to raise the attention of clinicians to this rare malignant transforming dermatosis, after long period of hiding back away, but back again [36,37], with the advent of new technology "thermotherapy, computers, and thermal vocations", so that it will not be neglected as it is being presently [38]. The significance of this reminder is that Eai might herald a cancer, and it may potentially evolve to a cancer, hence; Eai fluctuates between two cancers. This malignant tendency of Eai urged us to remind of.

\section{REFERENCES}

[1] E G. Graham, "Little Erythema Ab Igne," Proceedings of Roral Society of Medicine, Vol. 4, 1911, pp. 88-89.

[2] W. S. Levinbook, J. Mallett and J. M. Grant-Kels, "Laptop Computer-Associated Erythema Ab Igne," Cutis, Vol. 80, No. 4, 2007, pp. 319-320.

[3] J. R. White Jr., "Miscellaneous Inflammatory Disorders," In: Moschella \& Hurley Dermatology, 3rd Edition, Chapter 25, WB Saunders Co, Philadelphia, 1993, pp. 600-601.

[4] J. J. Meffert and B. M. Davis, "Furniture-Induced Erythema Ab Igne," Journal of the American Academy of
Dermatology, Vol. 34, No. 3, 1996, pp. 516-517. doi:10.1016/S0190-9622(96)90463-6

[5] T. N. Helm, G. T. Spigel and K. F. Helm, "Erythema Ab Igne Caused by a Car Heater," Cutis, Vol. 59, No. 2, 1997, pp. 81-82.

[6] A. W. Arnold and P. H. Itin, "Laptop Computer-Induced Erythema Ab Igne in a Child and Review of the Literature," Pediatrics, Vol. 126, No. 5, 2010, pp. e1227-e1230. doi:10.1542/peds.2010-1390

[7] F. Andersen, "Laptop-Thighs - Laptop-Induced Erythema Ab Igne," Ugeskr Laeger, Vol. 172, No. 8, 2010, p. 635.

[8] M. J. Boffa, "Laptop Computer-Induced Erythema Ab Igne on the Left Breast," Cutis, Vol. 87, No. 4, 2011, pp. $175-176$

[9] S. Giraldi, F. Diettrich, K. T. Abbage, O. Carvalho Vde and L. P. Marinoni, "Erythema Ab Igne Induced by a Laptop Computer in an Adolescent," Anais Brasileiros de Dermatologia, Vol. 86, No. 1, 2011, pp. 128-130. doi:10.1590/S0365-05962011000100018

[10] J. F. Chen, Y. C. Liu, Y. F. Chen, C. P. Chiang and W. M. Wang, "Erythema Ab Igne after Footbath with Chinese Herbal Remedies," Journal of the Chinese Medical Association, Vol. 74, No. 1, 2011, pp. 51-53. doi:10.1016/j.jcma.2011.01.009

[11] M. P. Tighe, R. A. Morenas, N. A. Afzal and R. M. Beattie, "Erythema Ab Igne and Crohn's Disease," Archives of Disease in Childhood, Vol. 93, No. 5, 2008, p. 389. doi:10.1136/adc. 2008.137968

[12] K. G. Donohue, W. K. Nahm, E. Badiavas, L. Li and A. Pedvis-Leftick, "Hot Pop Brown Spot: Erythema Ab Igne Induced by Heated Popcorn," Journal of Dermatology, Vol. 29, No. 3, 2002, pp. 172-173.

[13] R. Parker and F. H. Gordon, "A Different Cause of Erythema Ab Igne in Chronic Pancreatitis," Pancreatology, Vol. 8, No. 4-5, 2008, p. 532. doi:10.1159/000152002

[14] J. MacHale, F. Chambers and P. R. O'Connell, "Erythema Ab Igne: An Unusual Manifestation of CancerRelated Pain," Pain, Vol. 87, No. 1, 2000, pp. 107-108. doi:10.1016/S0304-3959(00)00265-7

[15] K. Chandramohan, P. V. Bhagwat, T. Arun and S. E. Mohan, "Erythema Ab Igne of Chest in a Patient with Pulmonary Tuberculosis," Indian Journal of Dermatology, Vol. 56, No. 2, 2011, p. 233. doi:10.4103/0019-5154.80435

[16] R. P. Dellavalle and P. Gillum, "Erythema Ab Igne Following Heating/Cooling Blanket Use in the Intensive Care Unit," Cutis, Vol. 66, No. 2, 2000, pp. 136-138.

[17] J. K. Chan and L. H. Yap, "Comment on 'Clinical Tip: Erythema Ab Igne' Following Implant-Based Breast Reconstruction," Journal of Plastic, Reconstructive \& Aesthetic Surgery, Vol. 62, No. 1, 2009, pp. 119-120. doi:10.1016/j.bjps.2008.09.005

[18] D. W. H. Mok and L. H. Blumgart, "Erythema Ab Igne in Chronic Pancreatic Pain: A Diagnostic Sign," Journal of the Royal Society of Medicine, Vol. 77, 1984, pp. 299301.

[19] M. Ashby, "Erythema Ab Igne in Cancer Patients," Journal of the Royal Society of Medicine, Vol. 78, 1985, pp. 
925-928

[20] A. R. Molina, N. Behar and R. Bhardwaj, "Rectal Cancer Presenting with Erythema Ab Igne," Journal of the Royal Society of Medicine: Short Reports, Vol. 1, No. 6, 2010, p. 48. doi:10.1258/shorts.2010.100034

[21] M. Sesay and S. Dhanji, "Case Report: Erythema Ab Igne in a Patient with Diabetic Neuropathy," American Family Physician, Vol. 80, No. 4, 2009, p. 322.

[22] C. T. C. Kennedy, "Mechanical and Thermal Injury," In: W. E. Rook, Ed., Textbook of Dermatology, 6th Edition, Blackwell Science, Vol. 23, 1998, pp. 937-938.

[23] J. Fischer, K. Rein, C. Erfurt-Berge and M. de Zwaan, "Three Cases of Erythma Ab Igne (EAI) in Patients with Eating Disorders," Neuropsychiatr, Vol. 24, No. 2, 2010, pp. 141-143.

[24] R. R. Riahi, P. R. Cohen, F. W. Robinson and J. M. Gray, "Erythema Ab Igne Mimicking Livedo Reticularis," International Journal of Dermatology, Vol. 49, No. 11, 2010, pp. 1314-1317. doi:10.1111/j.1365-4632.2009.04433.x

[25] A. Joyce, T. D. Horn and G. J. Anhalt, "Prurigo Pigmentosa: Report of a Case and Review of Literature," Archives of Dermatology, Vol. 125, 1989, pp. 1551-1554. doi:10.1001/archderm.1989.01670230093017

[26] P. Sharood and R. Marks, "The Waves of Warmth Changes in Erythema Ab Igne," British Journal of Dermatology, Vol. 97, 1977, pp. 179-186. doi:10.1111/j.1365-2133.1977.tb15063.x

[27] J. Akasaka and S. Kon, "Two Cases of Squamous Cell Carcinoma Arising from Erythema Ab Igne," Nippon Hifuka Gakkai Zasshi, Vol. 99, 1977, pp. 735-734.

[28] H. B. Hewitt, A. Sherif, K. M. Kerr, et al., "Markel Cell and Squamous Cell Carcinoma Arising in Erythema $\mathrm{Ab}$ Igne. (Letter)," British Journal of Dermatology, Vol. 128, 1993, pp. 591-592. doi:10.1111/j.1365-2133.1993.tb00247.x

[29] M. V. Iacocca, J. L. Abernethy, C. M. Stefanato, A. E. Allan and J. Bhawan, "Mixed Merkel Cell Carcinoma and Squamous Cell Carcinoma of the Skin," Journal of the American Academy of Dermatology, Vol. 39, No. 5, 1998, pp. 882-887. doi:10.1016/S0190-9622(98)70372-X

[30] J. Wharton, D. Roffwarg, J. Miller and D. J. Sheehan,
"Cutaneous Marginal Zone Lymphoma Arising in the Setting of Erythema Ab Igne," Journal of the American Academy of Dermatology, Vol. 62, No. 6, 2010, pp. 10801081. doi:10.1016/i.jaad.2009.08.005

[31] M. A. Teli, N. A. Khan, M. A. Darzi, M. Gupta and A. Tufail, "Recurrence Pattern in Squamous Cell Carcinoma of Skin of Lower Extremities and Abdominal Wall (Kangri Cancer) in Kashmir Valley of Indian Subcontinent: Impact of Various Treatment Modalities," Indian Journal of Dermatology, Vol. 54, No. 4, 2009, pp. 342-346. doi:10.4103/0019-5154.57610

[32] C. Kochs, S. Hanneken, K. W. Schulte and J. Reifenberger, "Treatment of Carcinoma in Situ of Erythema Ab Igne with Photodynamic Therapy," Hautarzt, Vol. 59, No. 10, 2008, pp. 777-779. doi:10.1007/s00105-008-1634-8

[33] A. Sood, S. Sharma and N. Khanna, "Cutaneous Horn and Thermal Keratosis in Erythema AB Igne," Indian Journal of Dermatology, Venereology and Leprology, Vol. 68, No. 4, 2002, pp. 237-238.

[34] T. Mitsuhashi, T. Hirose, A. Kuramochi, T. Tsuchida and M. Shimizu, "Cutaneous Reactive Angiomatosis Occurring in Erythema Ab Igne Can Cause Atypia in Endothelial Cells: Potential Mimic of Malignant Vascular Neoplasm," Pathology International, Vol. 55, No. 7, 2005, pp. 431-435. doi:10.1111/j.1440-1827.2005.01849.x

[35] S. Cho, J. Y. Jung and J. H. Lee, "Erythema Ab Igne Successfully Treated Using 1064-nm Q-Switched Neodymium-Doped Yttrium Aluminum Garnet Laser with Low Fluence," Dermatologic Surgery, Vol. 37, No. 4, 2011, pp. 551-553. doi:10.1111/j.1524-4725.2011.01923.x

[36] S. Tan and V. Bertucci, "Erythema Ab Igne: An Old Condition New Again," Canadian Medical Association Journal, Vol. 162, No. 1, 2000, pp. 77-78.

[37] M. Karlsson and Y. W. Linde, "Erythema Ab IgneClassical Dermatological Diagnosis Hot Again. Laptop Computer Dermatitis Most Common in Young People," Lakartidningen, Vol. 107, No. 32-33, 2010, p. 1844.

[38] A. M. Baruchin, "Erythema Ab Igne-A Neglected Entity?" Burns, Vol. 20, No. 5, 1994, pp. 460-462. doi:10.1016/0305-4179(94)90043-4 